\title{
Flow-through solid-phase based optical sensor for the multisyringe flow injection trace determination of orthophosphate in waters with chemiluminescence detection ${ }^{\text {is }}$
}

\author{
Inês P.A. Morais ${ }^{\mathrm{a}}$, Manuel Miró ${ }^{\mathrm{b}}$, Matias Manera ${ }^{\mathrm{b}}$, José Manuel Estela ${ }^{\mathrm{b}}$, \\ Víctor Cerdà ${ }^{\mathrm{b}}$, M. Renata S. Souto ${ }^{\mathrm{a}}$, António O.S.S. Rangel ${ }^{\mathrm{a}, *}$ \\ ${ }^{a}$ Escola Superior de Biotecnologia, Universidade Católica Portuguesa, R. Dr. António Bernardino de Almeida, 4200-072 Porto, Portugal \\ ${ }^{\mathrm{b}}$ Department of Chemistry, Faculty of Sciences, University of the Balearic Islands, Carretera de Valldemossa Km 7.5, 07122 Palma de Mallorca, Spain
}

Keywords: Multisyringe flow injection analysis; Solid-phase optical sensor; Chemiluminescence; Orthophosphate determination; Waters

\begin{abstract}
In this work, a novel flow-through solid-phase based chemiluminescence (CL) optical sensor is described for the trace determination of orthophosphate in waters exploiting the multisyringe flow injection analysis (MSFIA) concept with multicommutation. The proposed time-based injection flow system relies upon the in-line derivatisation of the analyte with ammonium molybdate in the presence of vanadate, and the transient immobilisation of the resulting heteropolyacid in a $N$-vinylpyrrolidone/divinylbenzene copolymer packed spiral shape flow-through cell located in front of the window of a photomultiplier tube. The simultaneous injection of well-defined slugs of luminol in alkaline medium and methanol solution towards the packed reactor is afterwards performed by proper switching of the solenoid valves. Then, the light emission from the luminol oxidation by the oxidant species retained onto the sorbent material is readily detected. At the same time, the generated molybdenum-blue compound is eluted by the minute amount of injected methanol, rendering the system prepared for a new measuring cycle. Therefore, the devised sensor enables the integration of the solid-phase CL reaction with elution and detection of the emitted light without the typical drawbacks of the molybdenum-blue based spectrophotometric procedures regarding the excess of molybdate anion, which causes high background signals due to its self-reduction. The noteworthy features of the developed CL-MSFIA system are the feasibility to accommodate reactions with different $\mathrm{pH}$ requirements and the ability to determine trace levels of orthophosphate in high silicate content samples (Si/P ratios up to 500). Under the optimised conditions, a dynamic linear range from 5 to $50 \mu \mathrm{g} \mathrm{Pl}^{-1}$ for a $1.8 \mathrm{ml} \mathrm{sample}$, repeatability better than $3.0 \%$ and a quantification limit of $4 \mu \mathrm{g} \mathrm{Pl}^{-1}$ were attained. The flowing stream system handles 11 analysis $\mathrm{h}^{-1}$ and has been successfully applied to the determination of trace levels of orthophosphate in environmental samples such as mineral, ground, tap and pond waters as well as samples from a water-steam cycle of an incineration plant. The $t$-test comparison of the means for the developed optical sensor and the molybdenum-blue spectrophotometric APHA/AWWA/WPCF reference method revealed that there is no evidence of significant differences between the obtained results at the $95 \%$ confidence level.
\end{abstract}

\footnotetext{
Presented at the Flow Analysis IX Conference, Geelong, Australia, 17-21 February 2003.

* Corresponding author. Tel.: +351-2-5580064; fax: +351-22-5090351.

E-mail address: rangel@esb.ucp.pt (A.O.S.S. Rangel).
}

\section{Introduction}

The analytical interest of chemiluminescence (CL) reactions has been increasing over the past years due to its high sensitivity, low detection limits and wide linear range [1]. Moreover, CL methodologies become an attractive alternative to conventional procedures as can be implemented with straightforward and economical equipment. These features are even maximised if associated with flow systems, whose precise timing enables increased repeatability. Easier sample handling, reduced reagent consumption and improvement of analysis throughput are also guaranteed with the exploitation of flow techniques. Multisyringe flow injection analysis (MSFIA) [2] scheme has been recently proposed as an evolution to both flow injection (FIA) [3] and sequential injection (SIA) [4] systems. This novel flowing stream 
principle use a propulsion device named multisyringe which is a multiple channel piston pump, driven by a single motor of an automatic burette and controlled by computer software through a serial port. A three-way solenoid valve, analogous to those employed in the multicommutation scheme [5], is connected to the head of each syringe, allowing optional coupling to the manifold lines, both in dispense and aspirate movements of the liquid driver [6]. MSFIA includes the outstanding features pointed out to sequential and flow injection methodologies, namely robustness, flexibility, low reagent consumption and simultaneous flow of solutions, that enables the mixing of sample and reagents in proper confluence points. The main limitation of this approach is the movement of the four syringes in block; once the dispensing volume and the flow rate have been selected for one of the syringes, the values for the others become automatically defined and depend exclusively on the syringe size [7]. Additionally, as the forward movement must be stopped after several operations to reload the syringes the sampling frequency, alike SIA systems, decreases in comparison with FIA assemblies [6], being however sufficient for monitoring purposes.

The interfacing of the MSFIA scheme with CL detection has recently been presented as a powerful combination for fast CL reactions in homogeneous phase [8] overcoming the Achilles' heel of classical FIA and multicommutation approaches related to the ageing of Tygon tubing and the impossibility of other syringe pump-based flowing stream methods, such as SIA, to be adapted to the fast kinetics of the $\mathrm{CL}$ reactions involving luminol oxidation.

In this paper, an automated time-based injection CLMSFIA system relied upon the luminol oxidation by the vanadomolybdophosphate complex immobilised in a spiral-shaped flow cell containing the $N$-vinylpyrrolidone/ divinylbenzene copolymer is reported for the determination of orthophosphate at low $\mu \mathrm{g} 1^{-1}$ levels in unpolluted waters. To the best of our knowledge, this is the first CL-based solid-phase flow-through optical sensor devised for the automatic determination of orthophosphate at trace levels. The multicommuted-MSFIA assembly performs the in-line formation of the vanadomolybdophosphate species, which is retained downstream in the flow-through cell packed with the hydrophobic/hydrophilic copolymer and placed in front of the window of a photomultiplier tube. Following clean-up steps, the immobilised complex is determined by CL detection capitalizing on its ability to oxidize organic molecules, such as 3-aminophthalhydrazide (luminol), with the subsequent light emission. The in-line addition of methanol to the luminol solution enables simultaneously the elution of the reduced heteropolyacid without observing neither quenching effects nor signal depressing as a consequence of the fast kinetics of the luminol-based CL reaction. The feasibility to integrate the solid-phase CL reaction with detection of the emitted light and elution of the adsorbed species through a multicommutation protocol is thus demonstrated.
The proposed methodology is able to exploit consecutively two reactions with different $\mathrm{pH}$ requirements, that is, the in-line formation of the heteropolyacid in acidic conditions and the heterogeneous phase-CL reaction with luminol in alkaline medium without requiring additional neutralisation procedures as previously described in post-column ion-chromatography reactions [9]. Proper adjustment of the acidity in the first reaction [10] and kinetic discrimination of other heteropolyacid forming oxoanions such as silicate and arsenate [11,12], are to be considered as potential strategies aiming to minimize the interferences which hinder the real applicability of the conventional procedures devoted to orthophosphate monitoring [13], so that in the designed sensor neither selective masking agents as tartrate or oxalate [14] nor multivariate calibration approaches $[15,16]$ are needed. The usefulness of the developed flow-through CL optical sensor is demonstrated by the determination of trace levels of orthophosphate in environmental waters as well as water-steam cycle samples, being validated using the standard addition technique and the classical molybdenum-blue spectrophotometric method.

\section{Experimental}

\section{Reagents and solutions}

All solutions were prepared using analytical-reagent grade chemicals and boiled distilled water was used throughout. A stock standard solution of orthophosphate with concentration corresponding to $50 \mathrm{mg} \mathrm{Pl}^{-1}$ was obtained by dissolving $0.22 \mathrm{~g}$ of $\mathrm{KH}_{2} \mathrm{PO}_{4}$ (Probus) in water and diluting to $1000 \mathrm{ml}$. Working standard solutions were prepared daily by serial dilution of the stock solution. A reagent solution containing $1.5 \times 10^{-3} \mathrm{M}$ ammonium molybdate and $1.5 \times 10^{-3} \mathrm{M}$ ammonium vanadate was prepared from $\left(\mathrm{NH}_{4}\right)_{6} \mathrm{Mo}_{7} \mathrm{O}_{24} \cdot 4 \mathrm{H}_{2} \mathrm{O}$ (Panreac) and $\mathrm{NH}_{4} \mathrm{VO}_{3}$ (Probus) in a $0.2 \mathrm{M} \mathrm{H}_{2} \mathrm{SO}_{4}$ medium. An $80 \%$ (v/v) methanol solution in water was used as eluent. This solution was degassed in an ultrasonic bath for $15 \mathrm{~min}$ before injection into the flowing system.

The chemiluminogenic reagent consisted of $0.0868 \mathrm{~g}$ of 3-aminophthalhydrazide (luminol, 98\%, Acrós organics) dissolved in $1.75 \mathrm{ml}$ of $2 \mathrm{M} \mathrm{NaOH}$ and made up to $100 \mathrm{ml}$ with water. According to Bowie et al. [17], the chemiluminogenic reagent is stable for at least 1 month at a $\mathrm{pH}>$ 12.0. Thus, the chemiluminescence methodology is more suitable for monitoring schemes than the conventional spectrophotometric molybdenum-blue method involving unstable reducing reagents (viz. ascorbic acid or tin(II) chloride), which are recommended to be prepared daily [18].

For heteropolyacid pre-concentration, a $N$-vinylpyrrolidone/divinylbenzene sorbent (Oasis ${ }^{\circledR}$ HLB, Waters) with an average particle size of $30 \mu \mathrm{m}$ and pore diameter of $80 \AA$ was used to assemble the solid-phase optical sensor. The spiral-shaped flow-through cell was filled with the beads 


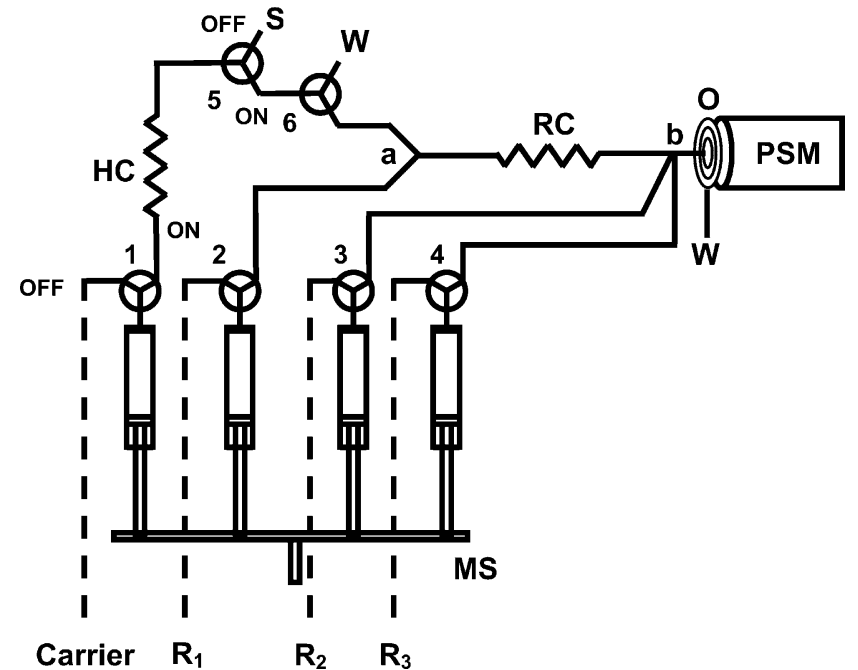

Fig. 1. Manifold for the determination of trace levels of orthophosphate in waters using the designed flow-through MSFIA-CL optical sensor. MS: multisyringe; PSM: photosensor module; $(\mathrm{O})$ flow-through solid-phase optical sensor; HC: holding coil $(230 \mathrm{~cm})$; RC: reaction coil $(160 \mathrm{~cm})$; (a and b) confluences; W: waste; S: sample or standard; Carrier: distilled water; $R_{1}=1.5 \times 10^{-3} \mathrm{M}$ ammonium molybdate and $1.5 \times 10^{-3} \mathrm{M}$ ammonium vanadate in $0.2 \mathrm{M} \mathrm{H}_{2} \mathrm{SO}_{4} ; R_{2}=5 \times 10^{-3} \mathrm{M}$ luminol in $0.035 \mathrm{M} \mathrm{NaOH} ; R_{3}=80 \%(\mathrm{v} / \mathrm{v}) \mathrm{MeOH}$.

previously suspended in distilled water by positive pressure using a peristaltic pump. A polyethylene retaining frit with an average pore diameter of $10 \mu \mathrm{m}$ was located at the flow cell outlet. At the end of each working day, the packed column was washed with a $2 \mathrm{M} \mathrm{NaOH}$ solution to minimize the coating effect [19] and thus, the sensor life-time was prolonged to at least 10 days.

\section{Instrumentation and flow system}

A multisyringe device with programmable speed (MicroBU 2030, Crison, Alella, Barcelona, Spain) was used as a liquid driver [20]. It was equipped with four syringes with different volumes: $2.5 \mathrm{ml}$ in positions 1,2 and 3 and $1 \mathrm{ml}$ in position 4 as shown in Fig. 1. A three-way commutation valve ( $N$-Research, Caldwell, NJ, USA) was connected to the head of each syringe; two extra solenoid valves were included in the module assembled, allowing sample aspiration and rinse between consecutive samples.

The holding coil (HC) was made of $1.5 \mathrm{~mm}$ i.d. polytetrafluoroethylene (PTFE) tube, the length being $230 \mathrm{~cm}$, corresponding to ca. $4.1 \mathrm{ml}$. All the other connections were made with PTFE of $0.8 \mathrm{~mm}$ i.d. The reaction coil (RC) was constructed by interlacing a $160 \mathrm{~cm}$ long PTFE tubing in knots of ca. $5 \mathrm{~mm}$ diameter. Three and four-way poly(methylmethacrylate) (PMMA) connectors were used as confluences for the different reactions taking place in the flow set-up.

The laboratory-made chemiluminescence detector arranged in a light tight home made box included: a Hamamatsu HS5784-04 photosensor module $(185-850 \mathrm{~nm})$, a
PMMA spiral-shaped flow-through cell with an internal volume of $120 \mu \mathrm{l}$, a 10-bit analogue to digital converter with eight analog input channels and a serial RS485 output and a RS485 to RS232C converter card [8]. A noteworthy feature of the devised CL detector is the capability to adjust the sensitivity of the analysis through the selection of the proper value for the voltage of the implemented feedback circuit, which allows the control of the detector gain. Experimental control, data acquisition and treatment were carried out with the Autoanalysis software package (http://go.to/AEST) written in Delphi (version 5.0) and Visual $\mathrm{C}++$ (version 6.0).

\section{Procedure for chemiluminescence assays using the developed optical sensor}

The CL determination of trace concentrations of orthophosphate was performed according to the operational sequence given in Table 1 . Syringes 1, 2, 3 and 4 contain carrier (water), molybdate/vanadate solution, luminol in alkaline medium and methanol, respectively. Initially, all solenoid valves were switched to 'OFF' position. The first three steps of the MSFIA protocol involve the change of sample/standard solution in order to avoid carryover effects between consecutive runs, being capitalised on the special configuration of the designed manifold with valve 6 connected to waste. In these steps, the sample is drawn up through solenoid valve 5 in 'OFF' position, cleaning the loading tube with the new solution; then with valve 6 directed to waste and switching on valve 5, the $\mathrm{HC}$ is flushed with water. A well-defined volume of sample solution is afterwards aspirated into the $\mathrm{HC}$ using syringe 1, when solenoid valve 5 is turned 'OFF' and keeping valve 1 ' $\mathrm{ON}$ ' (step 5). Subsequently, with valves 1, 2, 5 and 6 activated to 'ON' position, sample and molybdate/vanadate solutions are delivered to the three-way confluence (a), whereupon the injected zones merge to form the heteropolyacid species, which was continuously retained in the solid-phase packed flow-through cell (step 6). After assuring that all the heteropolyacid formed in the $\mathrm{RC}$ was adsorbed on the polymeric material, following sorbent clean-up (step 8), valves 3 and 4 are switched to 'ON' position. Minute plugs of luminol and methanol are then introduced into the system, interdispersed at the four-way connector (confluence b) and driven to the flow detector, wherein the CL reaction and elution of the reduced compound take place (step 10). The ratio of 1:0.4 between luminol and methanol solutions (based on the syringe volumes) enabled to carry on the CL reaction and the elution process in the same step, without loss of sensitivity.

\section{Reference batch APHA/AWWA/WPCF spectrophotometric method}

Ammonium molybdate reacts in acidic medium with orthophosphate in the presence of potassium antimonyl tartrate 
Table 1

Operational protocol for the determination of orthophosphate in waters using the devised CL-MSFIA optical sensor ${ }^{\mathrm{a}}$

\begin{tabular}{|c|c|c|c|c|c|c|c|c|}
\hline \multirow[t]{2}{*}{ Step } & \multirow[t]{2}{*}{ Operation } & \multicolumn{6}{|c|}{ Valve position } & \multirow[t]{2}{*}{ Description } \\
\hline & & 1 & 2 & 3 & 4 & 5 & 6 & \\
\hline 1 & Dispense $0.6 \mathrm{ml}$ at $7.5 \mathrm{ml} \mathrm{min}^{-1}$ & $\mathrm{OFF}$ & OFF & $\mathrm{OFF}$ & $\mathrm{OFF}$ & $\mathrm{OFF}$ & $\mathrm{OFF}$ & Piston bar adjustment \\
\hline 2 & Pickup $0.6 \mathrm{ml}$ at $4 \mathrm{ml} \mathrm{min}-1$ & ON & OFF & OFF & OFF & OFF & OFF & Washing of sampling channel \\
\hline 3 & Dispense $1.8 \mathrm{ml}$ at $7.5 \mathrm{ml} \mathrm{min}-1$ & ON & $\mathrm{OFF}$ & $\mathrm{OFF}$ & $\mathrm{OFF}$ & ON & $\mathrm{OFF}$ & Dispense carrier solution to rinse the $\mathrm{HC}$ \\
\hline 4 & Start loop & & & & & & & \\
\hline 5 & Pickup $1.8 \mathrm{ml}$ at $4 \mathrm{ml} \mathrm{min}^{-1}$ & $\mathrm{ON}$ & OFF & $\mathrm{OFF}$ & $\mathrm{OFF}$ & $\mathrm{OFF}$ & $\mathrm{OFF}$ & Aspirate sample zone into the $\mathrm{HC}$ \\
\hline 6 & Dispense $2 \mathrm{ml}$ at $1.1 \mathrm{ml} \mathrm{min}^{-1}$ & ON & ON & $\mathrm{OFF}$ & $\mathrm{OFF}$ & $\mathrm{ON}$ & ON & $\begin{array}{l}\text { Dispense sample and molybdate/vanadate } \\
\text { plugs to the RC, taking place the } \\
\text { heteropolyacid formation and } \\
\text { preconcentration onto the sorbent }\end{array}$ \\
\hline 7 & Pickup $2 \mathrm{ml}$ at $7.5 \mathrm{ml} \mathrm{min}^{-1}$ & $\mathrm{OFF}$ & $\mathrm{OFF}$ & $\mathrm{OFF}$ & $\mathrm{OFF}$ & $\mathrm{ON}$ & $\mathrm{ON}$ & Piston bar adjustment \\
\hline 8 & Dispense $1.3 \mathrm{ml}$ at $0.5 \mathrm{ml} \mathrm{min}^{-1}$ & $\mathrm{ON}$ & $\mathrm{OFF}$ & $\mathrm{OFF}$ & $\mathrm{OFF}$ & $\mathrm{ON}$ & $\mathrm{ON}$ & $\begin{array}{l}\text { Dispense carrier solution to rinse the } \mathrm{RC} \\
\text { and packed reactor }\end{array}$ \\
\hline 9 & $\begin{array}{l}\text { Start to collect the emitted light }(\lambda \\
\sim 425 \mathrm{~nm}) \text { at high reading speed } \\
\text { with a feedback voltage of } 0.7 \mathrm{~V}\end{array}$ & & & & & & & 14 readings $s^{-1}$ \\
\hline 10 & Dispense $0.15 \mathrm{ml}$ at $1.4 \mathrm{ml} \mathrm{min}^{-1}$ & $\mathrm{OFF}$ & $\mathrm{OFF}$ & $\mathrm{ON}$ & ON & $\mathrm{OFF}$ & $\mathrm{OFF}$ & $\begin{array}{l}\text { Dispense luminol and methanol slugs to } \\
\text { the detector; taking place the CL reaction } \\
\text { and elution }\end{array}$ \\
\hline 11 & Dispense $0.15 \mathrm{ml}$ at $2 \mathrm{ml} \mathrm{min}^{-1}$ & ON & $\mathrm{OFF}$ & $\mathrm{OFF}$ & $\mathrm{OFF}$ & $\mathrm{ON}$ & $\mathrm{ON}$ & $\begin{array}{l}\text { Dispense carrier solution through the } \\
\text { flow-cell to recover the base line }\end{array}$ \\
\hline 12 & Stop measurement & & & & & & & \\
\hline 13 & Dispense $0.2 \mathrm{ml}$ at $7.5 \mathrm{ml} \mathrm{min}^{-1}$ & $\mathrm{OFF}$ & $\mathrm{OFF}$ & $\mathrm{OFF}$ & OFF & $\mathrm{OFF}$ & $\mathrm{OFF}$ & Piston bar adjustment \\
\hline 14 & Repeat $n$ times from loop & & & & & & & $\mathrm{n}$ : number of injections \\
\hline
\end{tabular}

${ }^{a}$ The indicated values of flow rate and volume are referred to syringe 1.

to form an heteropolyacid compound, that is then reduced to molybdenum-blue with ascorbic acid [18]. The absorbance is measured at $710 \mathrm{~nm}$, and the orthophosphate concentration is determined using a calibration graph with linear dynamic range from 0.10 to $1.30 \mathrm{mg} \mathrm{Pl}^{-1}$.

\section{Results and discussion}

Preliminary assays on the performance of the solid-phase CL-optical sensor were carried out using a multicommuted flow system that relied on the use of a peristaltic pump furnished with elastic Tygon tubing as a liquid driver. Nonetheless, the continuous ageing of the flexible tubes leads to an unpaired performance when exploiting time-based injection strategies and imposes daily recalibration of the flow system. With the replacement of the peristaltic system by syringe pumps assembled in a multisyringe module, the severe aforementioned drawbacks were overcome and hence, a substantial improvement in robustness was achieved.

The developed time-based MSFIA optical sensor depicted in Fig. 1 for the determination of low $\mu \mathrm{gl}^{-1}$ levels of orthophosphate in unpolluted waters relies upon the integration of the CL reaction, that is the luminol oxidation by the immobilised heteropolyacid compound in the flow-cell, with detection of the emitted light as well as elution of the blue complex formed. Initially, sample and the acidic molybdate/vanadate slugs were drawn up and mixed in a $\mathrm{T}$-confluence to form the vanadomolybdophosphoric complex, which was continuously retained in the $\mathrm{N}$ vinylpyrrolidone/divinylbenzene copolymeric material (Oasis ${ }^{\circledR}$ HLB), by both physical adsorption and polar interactions. Luminol and methanol were then injected in the flow system, merged in a 4-way connector, and driven to the flow-through optical sensor for CL measurement, rendering the system ready for a new analytical cycle.

After an initial assessment to select approximate values for each parameter, optimisation of the different variables was performed using a univariate method due to the physical and temporal separation of both the complexation and chemiluminescence reactions involved in the flowing stream system. These studies were carried out comparing the difference between the CL-analytical signal recorded with a standard solution containing $50 \mu \mathrm{g} \mathrm{Pl}^{-1}$ and the blank signal.

\section{Selection of the sorben tmaterial}

Preliminary batch studies were carried out aiming to select the proper solid material to perform the in-line vanadomolybdophosphoric acid pre-concentration. Initially, octadecyl $\left(\mathrm{C}_{18}\right)$-chemically modified silica-gel columns were tested considering previously reported results for the immobilisation of heteropoly complexes [16]. Nevertheless, the vanadomolybdophosphoric acid exhibited a low retention coefficient in this material with high longitudinal distribution and analyte breakthrough after preconcentration of only a few $\mu$ l of sample. The high polarity of the heteropolyacid complex accounted for the fact that it could not be retained 
by reversed-phase adsorption on the $\mathrm{C}_{18}$-bead material. Besides, the silica gel support would be hydrolysed in the alkaline medium $(\mathrm{pH}>9)$ required for the CL-oxidation of luminol, which in turn would hinder the long-term applicability of the optical sensor as a consequence of the cleavage of active sites. Taking the polarity of the complex into account, the use of traditional non-polar copolymeric beads, viz. styrene-divinylbenzene, was also disregarded. The novel $N$-vinylpyrrolidone/divinylbenzene copolymer, including a hydrophilic/hydrophobic balance, was selected as the most suitable solid phase for the designed CL-sensor. Unlike $\mathrm{C}_{18}$-columns, no pre-elution effect due to the analyte solvent itself was detected with the selected copolymeric solid-phase when low loading rates are used.

\section{Investigation of chemical variables}

Regarding the in-line heteropolyacid formation in homogeneous phase, ammonium molybdate concentrations ranging from $5 \times 10^{-4}$ to $5 \times 10^{-3} \mathrm{M}$ in $0.4 \mathrm{M}$ nitric acid were assayed. A $1.5 \times 10^{-3} \mathrm{M}$ molybdate concentration was selected as an optimum value since the CL signal for a $50 \mu \mathrm{g} \mathrm{Pl}^{-1}$ standard solution increased up to this level and the blank signal produced as a consequence of the molybdate self-reduction remained at a minimum value as shown in Fig. 2. Hence, as opposed to the conventional spectrophotometric method, an excess of molybdate does not cause increased background signals, which is attributed to the different sorption behaviour of molybdate and heteropolyacid species on the copolymeric support.

The addition of ammonium metavanadate to an acidic molybdate reagent mixture was considered aiming to form the best heteropoly species for CL determination of trace concentrations of phosphorus(V) using the luminol chemistry [9]. Different solutions of $1.5 \times 10^{-3} \mathrm{M}$ ammonium molybdate containing $0,1 \times 10^{-3}, 1.5 \times 10^{-3}$ and $2.5 \times$ $10^{-3} \mathrm{M}$ ammonium metavanadate were tested. The $1.5 \times$ $10^{-3} \mathrm{M}$ solution was selected as the optical sensor signals increased up to this concentration. This effect might be attributed to the decrease on the reduction potential of the complex in the presence of $\mathrm{V}(\mathrm{V})$. To improve sensitivity, the

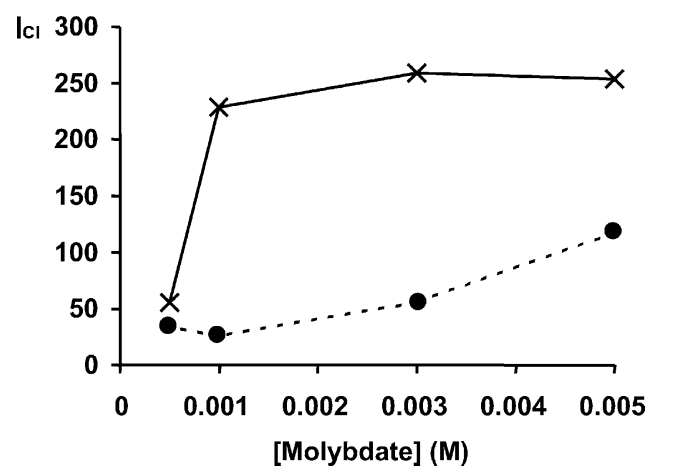

Fig. 2. Influence of molybdate concentration in the analytical $(x)$ and blank ( CL-MSFIA signals using a standard solution of $50 \mu \mathrm{g} \mathrm{Pl} l^{-1}$. addition of antimony to the ammonium molybdate solution, reported to catalyse the reduction of the heteropolyacid complexes [16] and contribute to the formation of the antimonylmolybdophosphorous species [19] was assayed. Increments of 30 and $42 \%$ on the CL signals were observed when using a $1.5 \times 10^{-3} \mathrm{M}$ ammonium molybdate solution containing $0.05 \mathrm{mM} \mathrm{Sb}$ or $1.5 \times 10^{-3} \mathrm{M} \mathrm{VO}_{3}{ }^{-}$, respectively. The latter solution was therefore chosen to improve the lower level of applicability of the sensor and avoid the incompatibility of the metalloid with the reaction media. Higher antimony concentrations are not recommended since a sharp drop in the analytical signal, viz. a five-fold decrease, is thus attained. As the vanadomolybdophosphate formation takes place in acidic medium, solutions containing $1.5 \times 10^{-3} \mathrm{M}$ ammonium molybdate and $1.5 \times 10^{-3} \mathrm{M}$ ammonium vanadate together with $0.4 \mathrm{M} \mathrm{H}_{3} \mathrm{O}^{+}$were prepared using $\mathrm{HNO}_{3}$, $\mathrm{HCl}$ and $\mathrm{H}_{2} \mathrm{SO}_{4}$ media. The $\mathrm{HCl}$ solution provided the lowest CL signals. A $50 \%$ increase in the recorded CL peak height was achieved when comparing the values obtained with the sulphuric acid solution with those of the nitric acid. This fact was probably due to the temperature rise during complex formation produced as a consequence of the dilution heat released into the system when merging sample and reagent $/ \mathrm{H}_{2} \mathrm{SO}_{4}$ plugs.

The acid concentration in the reaction medium prior solid-phase preconcentration is a critical parameter to take into account for the performance of the developed CL-sensor. It is known that acidity has opposite effects on the sensitivity and selectivity of the molybdate reaction $[9,19,21]$. Actually, an increase in the acid concentration level reduces silicate interference but produces a concomitantly decrease in the reaction sensitivity, while, low acid concentrations, even in the absence of orthophosphate, lead to self-reduction of molybdate [21-23]. For these reasons, sulphuric acid concentrations ranging from 0.10 to $0.30 \mathrm{M}$ were tested. As expected, the lower the acid concentration, the higher blank and CL analytical signals were encountered. Although the highest ratio between the analytical and blank signals was attained with a $0.15 \mathrm{M} \mathrm{H}_{2} \mathrm{SO}_{4}$ medium, a molybdate/vanadate reagent in $0.2 \mathrm{M} \mathrm{H}_{2} \mathrm{SO}_{4}$ was selected as a compromise between blank signal, analytical/blank signal ratio and potential silicate interference.

To provide an alkaline medium for the isolated luminolbased optical sensor reaction following heteropolyacid immobilisation and clean-up protocols, the chemiluminogenic reagent was dissolved in a sodium hydroxide solution aiming to ensure low background CL signals [8]. After testing several $8 \times 10^{-4} \mathrm{M}$ luminol solutions with sodium hydroxide concentrations comprised between 0.02 and $0.05 \mathrm{M}$, the $0.035 \mathrm{M} \mathrm{NaOH}$ solution was chosen for ensuing experiments since the highest CL signal was recorded without detecting an unduly increase of the blank signal. The influence of luminol concentration on the CL measurements in heterogeneous phase was studied over the range of $6 \times 10^{-4}$ to $7 \times 10^{-3} \mathrm{M}$. The results obtained pointed to a significant increase of peak height until $5 \times 10^{-3} \mathrm{M}$. The sensitivity 
decrease detected for higher luminol concentrations can be explained attending the contribution of self-absorption phenomena [8].

It is stressed in the literature that surfactants enhance the efficiency in the generation of molecules in excited state $[8,24]$, and therefore their effect in the described flow-through sensor was investigated. The influence of two surfactants, i.e. the anionic sodium dodecyl sulphate (SDS) and the cationic hexadecyl trimethyl ammonium chloride (HTAC), was assessed. A concentration of $0.5 \%$ (w/v) of each surfactant, that is above the critical micelle concentration in water, was added to the luminol solution. In both cases, the analytical signal as well as the repeatability decreased drastically (70 and $25 \%$, respectively) as compared with the assays without involving micellar medium. Furthermore, the progressive colour change of the copolymeric sorbent revealed the irreversible retention of the surfactants, entailing an unpaired performance of the developed optical sensor.

Previous studies pointed out that the CL reaction between luminol and an oxidant species is catalysed by traces of metals in alkaline medium $[25,26]$, and the kinetics of the formation of the blue heteropolyacid depends on the presence of metalloids in the reaction medium [16]. Therefore, cobalt and antimony were selected as potential catalysts. As both species can not be added to the luminol solution, due to precipitation of $\mathrm{Co}(\mathrm{OH})_{2}$ and hydrolysis of antimony, well-defined zones of reagents were injected into the system synchronously with the luminol and methanol zones using a new multicommutation protocol, the replacement of confluence $b$ in Fig. 1 with a five-way connector being required. However, no substantial improvement on the kinetics of the luminescence reaction was observed at any case, mainly attributed to the merely contribution of antimony to the formation of the oxidizing agent in the absence of vanadium(V) under steady-state conditions and the relevant influence of metal traces in CL reactions involving the generation of singlet oxygen species as an active chemiluminogenic agent.

\section{Investigation of physical variables}

The length, diameter, and configuration of the $\mathrm{RC}$ were selected taking exclusively into account the kinetic requirements of the heteropolyacid reaction since the fast CL process is integrated in the detection device. The length of the $\mathrm{RC}$ was as short as possible in order to minimize silicate interference, but ensuing an effective vanadomolybdophosphate formation. A knotted reaction coil was selected aiming to achieve a lower axial dispersion, a better reagent/sample radial mixing [27] and guarantee high reaction yields.

With the chemical variables set at the stated values in the foregoing section, the flow rate of the different steps of the experimental schedule listed in Table 1 was evaluated. No significant differences at the 5\% level were found for total flow rates ranging from 1.0 to $2.6 \mathrm{ml} \mathrm{min}^{-1}$ during the analyte derivatisation. A total flow rate of $2.2 \mathrm{ml} \mathrm{min}^{-1}$ was chosen, as larger values could provide the build-up of backpressure, or even clogging, which would deteriorate the solid-phase based system performance. The flow rate of the clean-up step was varied from 0.5 to $1.3 \mathrm{ml} \mathrm{min}^{-1}$. In this particular case, it is recommended to use the lowest rate achievable with the liquid-driver device considering the syringe dimensions, i.e. $0.5 \mathrm{ml} \mathrm{min}^{-1}$, as a signal depression for higher flow rates, attributed to the influence of the pre-elution effect, was observed. The total flow rate during the integrated $\mathrm{CL}$ reaction, detection and elution step was tested between 1.3 and $2.3 \mathrm{ml} \mathrm{min}^{-1}$. The $\mathrm{CL}$ analytical signal increased with increasing flow-rates due to the fast kinetics of the luminol oxidation [8]. In order to avoid an excessive compaction of the solid-phase material, a flow rate of $2.0 \mathrm{ml} \mathrm{min}^{-1}$ was chosen as a compromise between sensitivity and long-term applicability of the optical sensor.

The influence of the temperature in the heteropolyacid formation was also studied using an in-line thermostatic bath. As no considerable improvement in the CL analytical signal was observed between 28 and $40^{\circ} \mathrm{C}$, a temperature of $28^{\circ} \mathrm{C}$ (room temperature) was selected, since it is described that the higher temperature the more severe silicate interference is found [19].

\section{Analytical figures of merit}

Under the aforementioned chemical and physical conditions, and using a feedback voltage of $0.7 \mathrm{~V}$ allowing a gain value of 800 , a linear calibration graph was established over the range 5-50 $\mu \mathrm{g} \mathrm{Pl}^{-1}\left(I_{\mathrm{CL}}=110[\mathrm{P}]-497, r=0.9975\right)$. Although the linear range of the developed methodology is narrower than for most chemiluminescence methods, this can be explained by the fact that the CL reaction occurs between species presented in two different phases. This could lead to additional phenomena like the retention of the vanadomolybdophosphate complex in the solid phase placed outside the photomultiplier tube detection zone. Dynamic working ranges at high orthophosphate concentrations are straightforwardly attainable either by changing the gain voltage to a lower value or by reducing the injection loading time.

The limit of detection and quantification calculated as the concentration corresponding to the blank average (assessed by ten consecutive injections) plus three or ten times its standard deviation were 2 and $4 \mu \mathrm{gPl}{ }^{-1}$, respectively. Repeatability was estimated from 10 consecutive injections of three standard solutions. Relative standard deviations (R.S.D.s) of 2.6, 1.6 and 2.3\% were obtained for standards containing orthophosphate concentrations of 10.9, 31.1 and $44.4 \mu \mathrm{g} \mathrm{P}^{-1}$. The reproducibility calculated as the coefficient of variation obtained by analysing the same standard solution $\left(50 \mu \mathrm{g} \mathrm{P}^{-1}\right.$, three replicates) with three freshly packed solid-phase reactors was better than $3.0 \%$. The sampling throughput for a sampling volume of $1.8 \mathrm{ml}$ was $11 \mathrm{~h}^{-1}$. 


\section{Interference studies}

Although the proposed optosensor shows high tolerance to ionic sample constituents (e.g. dissolved salts) due to the selective homogeneous-phase reaction involved and the isolation step of the analyte on the copolymeric packed-bed resin, the CL method is subjected at different extents to the interference of heteropolyacid forming oxoanions such as arsenate and silicate. Silicate is often present in natural waters at concentrations that are one to three orders of magnitude higher than orthophosphate [19]. It is well documented that the rate of formation of silicomolybdate is much slower than the rate of formation of phosphomolybdate, as is also the rate of its reduction to the blue complex $[16,21]$. Hence, the maximum allowed flow rate for the in-line reaction without an unduly increase of flow resistance was selected. Under the optimised conditions, no interference of silicate was registered up to a $\mathrm{Si} / \mathrm{P}$ concentration ratio of 500, which involves a 125 -fold improvement with regard to the classical spectrophotometric vanadomolybdate method [13]. Higher concentration ratios led to a decrease in the analytical signal as a consequence of the competition between both complexes for the actives sites of the polymeric material. The high silicate tolerance exhibited for the flow-through optical sensor under dynamic conditions may be explained according to factors related with the different properties of both heteropolymolybdate species, namely, the capacity to be retained by the Oasis ${ }^{\circledR}$ HLB solid-phase, the retention being more effective for the vanadomolybdophosphate compound, and the lower potential of reduction of the phosphour-based heteropolyacid to the blue coloured complex.

Regarding arsenate, no additive interference at the 5\% level was detected when As and $\mathrm{P}$ were present at the same concentration level. Environmental samples, which usually present an arsenate concentration much lower than orthophosphate, can be readily analysed. In areas of arsenic pollution, arsenate interference could be avoided by previous addition of thiosulphate to reduce arsenate to arsenite, which is non-reactive to molybdate reagent [19]. No interference is expected from metal ions able to precipitate as hydroxyoxides (e.g. Fe) in the alkaline medium required for the CL reaction, since the analyte is separated from sample constituents under acidic conditions, by sorption of the vanadomolybdophosphoric acid complex on a copolymeric resin.

\section{Validation of the developed chemical sensor}

The applicability of the devised MSFIA CL-optical sensor was demonstrated through the determination of trace levels of orthophosphate in different environmental unpolluted samples, viz. mineral, ground, tap and pond water. Samples collected from a water-steam cycle of an incinerator plant, wherein orthophosphate is added at suitable $\mathrm{pH}$ with the aim of minimizing salt precipitation in the conduits
Table 2

Determination of orthophosphate in waters using both the devised MSFIA-CL optical sensor and the spectrophotometric molybdenum-blue reference method

\begin{tabular}{lllll}
\hline Sample & \multicolumn{4}{l}{ Orthophosphate found $\left(\mu \mathrm{g} \mathrm{P1}{ }^{-1}\right)$} \\
\cline { 2 - 5 } & MSFIA & $\begin{array}{l}\text { Reference } \\
\text { method }\end{array}$ & $\mathrm{RD}(\%)^{\mathrm{a}}$ & $t \mathrm{exp}^{\mathrm{b}}$ \\
\hline Ground water & $109 \pm 5$ & $112 \pm 4$ & -3.48 & 0.8 \\
Pond water & $136 \pm 3$ & $141 \pm 3$ & -3.55 & 2.0 \\
Boiler water (1) & $568 \pm 4$ & $564 \pm 6$ & +0.86 & 1.0 \\
Boiler water (2) & $487 \pm 5$ & $474 \pm 6$ & +2.74 & 2.5 \\
\hline
\end{tabular}

Results are expressed as the mean of three determinations \pm standard deviation.

a $\mathrm{RD}$, relative deviation.

b $t$ exp, $t$ experimental value; $t$ critical $(n=4,0.05)=2.78$.

of the cycle, were also analysed. Table 2 compares the experimental results obtained using the developed automated procedure with those of the standard APHA/AWWA/WPCF batch method [18], relied upon the photometric detection of the molybdenum-blue complex obtained by chemical reduction of $\mathrm{Mo}(\mathrm{VI})$ to $\mathrm{Mo}(\mathrm{V})$ in the heteropolyacid species. In order to bring the orthophosphate concentration within the linear working range of the MSFIA methodology, either a gain adjustment or a proper sample dilution was needed. No statistical differences were observed between the results obtained by both methodologies using a $t$-test comparison of the means [28] at a significance level of 0.05 and 4 degrees

Table 3

Recoveries of orthophosphate from unpolluted water samples determined using the proposed MSFIA sensor

\begin{tabular}{|c|c|c|c|}
\hline Sample & $\begin{array}{l}\text { Orthophosphate } \\
\text { added }\left(\mu \mathrm{gP} 1^{-1}\right)\end{array}$ & $\begin{array}{l}\text { Orthophosphate } \\
\text { found }\left(\mu g \mathrm{Pl}^{-1}\right)\end{array}$ & $\begin{array}{l}\text { Recovery } \\
(\%)\end{array}$ \\
\hline \multirow[t]{4}{*}{ Tap water } & - & $38.2 \pm 0.7$ & - \\
\hline & 10 & $49 \pm 1$ & 102.9 \\
\hline & 20 & $59.2 \pm 0.1$ & 101.7 \\
\hline & 30 & $69 \pm 2$ & 101.2 \\
\hline \multirow[t]{4}{*}{ Ground water (I) } & - & $17.7 \pm 0.9$ & - \\
\hline & 10 & $29.4 \pm 0.9$ & 106.1 \\
\hline & 20 & $40.6 \pm 0.4$ & 107.7 \\
\hline & 30 & $47 \pm 1$ & 97.9 \\
\hline \multirow[t]{4}{*}{ Mineral water } & - & $<\mathrm{DL}^{\mathrm{a}}$ & - \\
\hline & 5 & $5.1 \pm 0.2$ & 102.0 \\
\hline & 10 & $9.7 \pm 0.5$ & 97.0 \\
\hline & 20 & $19 \pm 1$ & 95.0 \\
\hline \multirow[t]{4}{*}{ Ground water (II) } & - & $30.64 \pm 0.02$ & - \\
\hline & 5 & $37.8 \pm 0.2$ & 106.0 \\
\hline & 10 & $41.2 \pm 0.5$ & 101.4 \\
\hline & 20 & $50 \pm 1$ & 98.7 \\
\hline \multirow[t]{4}{*}{ Vapour steam } & - & $28 \pm 2$ & - \\
\hline & 5 & $33.6 \pm 0.2$ & 101.8 \\
\hline & 10 & $35 \pm 2$ & 92.1 \\
\hline & 20 & $49.5 \pm 0.9$ & 103.1 \\
\hline
\end{tabular}

Results are expressed as the mean of three determinations \pm standard deviation.

${ }^{\mathrm{a}}$ Detection limit $=2 \mu \mathrm{g} \mathrm{P} 1^{-1}$. 
of freedom, since the $t$ critical value was higher than that of $t$ experimental for the entire set of samples analysed.

For unpolluted water samples with orthophosphate contents below the detection limit of the reference method but within the linear working range of the MSFIA methodology, the absence of multiplicative matrix interference was verified by the use of the standard addition method, since the amount of analyte added was recovered in all cases with a mean difference of $4.0 \%$ as shown in Table 3.

Although the CL-MSFIA optosensor has not been applied to saline waters, it should be stressed that the methodology is inherently free from chloride quenching because of the matrix removal step performed prior to CL detection.

\section{Conclusions}

A novel solid-phase based CL-MSFIA optical sensor based on the luminol oxidation by the heteropolyacid species immobilised in a $N$-vinylpyrrolidone/divinylbenzene copolymer packed spiral shape flow-through cell was developed for orthophosphate determination at the low $\mu \mathrm{g} \mathrm{l}^{-1}$ level in environmental water samples. Although the two reactions involved in this methodology, i.e. the formation of the heteropoly complex in an acidic medium and the CL reaction with luminol in alkaline conditions, have incompatible $\mathrm{pH}$ demands, no additional measures needed to be adopted in the devised sensor as both reactions are physically separated; that is, the injection of the alkaline luminol plug into the flowing system occurs merely following the adsorption of the in-line formed heteropolyacid species onto the copolymeric sorbent. Moreover, the different kinetic requirements of the complexation/chemiluminescence reactions and clean-up steps can be readily guaranteed through the wide range of flow rates accessible via the multisyringe flow instrumentation.

An unique feature of the designed optical sensor is the capability to integrate the solid-phase CL reaction with detection of the emitted light as well as elution of the reduced complex. It combines the advantages of flowing stream systems with the selectivity of the sensing element and exhibits great flexibility, easy miniaturisation and low cost. The high silicate tolerance level allowed, viz. a 500-fold Si/P concentration ratio, which makes it particularly suited for monitoring the measurand in environmental samples, is specially worthmentioning. Besides, the sensor is inherently free from interference of dissolved salts owing to the separation step of the derivatised analyte onto the copolymeric resin. It should be, however, mentioned that its application is restricted to environmental samples containing concomitantly low levels of organic matter (e.g. humic and fulvic acids) as a consequence of the irreversible sorption of high molecular weight compounds on the sensing microzone.

\section{Acknowledgements}

Inês P.A. Morais thanks Fundação para a Ciência e a Tecnologia (Portugal) for the grant PRAXIS XXI BD/20302/99. Manuel Miró is grateful for financial support granted by the Spanish Ministry of Science and Culture through the FPU program. The authors also extended their appreciation to the MCyT (Ministerio de Ciencia y Tecnología) for supporting the project PPQ2001-0474.

\section{References}

[1] A.M. García-Campaña, W.R. G.Baeyens, in: Chemiluminescence in Analytical Chemistry, Marcel Dekker, New York, 2001.

[2] V. Cerdà, J.M. Estela, R. Forteza, A. Cladera, E. Becerra, P. Altimira, P. Sitjar, Talanta 50 (1999) 695.

[3] J. Ruzicka, E.H. Hansen, Anal. Chim. Acta 78 (1975) 145.

[4] J. Ruzicka, G.D. Marshall, Anal. Chim. Acta 237 (1990) 329.

[5] B.F. Reis, M.F. Guiné, E.A.G. Zagatto, J.L.F.C. Lima, R.A. Lapa, Anal. Chim. Acta 293 (1994) 129.

[6] M.A. Segundo, A.O.S.S. Rangel, J. Flow Injection Anal. 19 (2002) 3.

[7] M. Miró, V. Cerdà, J.M. Estela, TrAC-Trends Anal. Chem. 21 (2002) 199.

[8] N. Pizà, M. Miró, G. Armas, E. Becerra, J.M. Estela, V. Cerdà, Anal. Chim. Acta 467 (2002) 155.

[9] T. Fujiwara, K. Kurahashi, T. Kumamaru, H. Sakai, Appl. Organometall. Chem. 10 (1996) 675.

[10] F. Mas-Torres, A. Muñoz, J.M. Estela, V. Cerdà, Analyst 122 (1997) 1033.

[11] H. Jiang, Z. Wang, J. Li, J. Lu, Fenxi Shiyanshi 16 (1997) 64.

[12] F. Mas-Torres, A. Muñoz, J.M. Estela, V. Cerdà, Int. J. Environ. Anal. Chem. 77 (2000) 185.

[13] A. Muñoz, F. Mas-Torres, J.M. Estela, V. Cerdà, Anal. Chim. Acta 350 (1997) 21.

[14] C.X. Galhardo, J.C. Masini, Anal. Chim. Acta 417 (2000) 191.

[15] A.K. Pettersson, B. Karlberg, Anal. Chim. Acta 378 (1999) 183.

[16] N. Lacy, G.D. Christian, J. Ruzicka, Anal. Chem. 62 (1990) 1482.

[17] A.R. Bowie, E.P. Achterberg, R.F.C. Mantoura, P.J. Worsfold, Anal. Chim. Acta 361 (1998) 189

[18] APHA-AWWA-WPCF, Standard Methods for the Examination of Water and Wastewater, 20th ed., American Public Health Association, American Water Works Association, Water Pollution Control Federation, Washington DC, 1998 (Chapter 4).

[19] J.-Z. Zhang, C.J. Fisher, P.B. Ortner, Talanta 49 (1999) 293

[20] F. Albertús, B. Horstkotte, A. Cladera, V. Cerdà, Analyst 124 (1999) 1373.

[21] S.-C. Pai, C.-C. Yang, J.P. Riley, Anal. Chim. Acta 229 (1990) 115.

[22] J.E. Going, S.J. Eisenreich, Anal. Chim. Acta 70 (1974) 95.

[23] J.F. Van Staden, R.E. Taljaard, Mikrochim. Acta 128 (1998) 223.

[24] C. Dodeigne, L. Thunus, R. Lejeune, Talanta 51 (2000) 415.

[25] W. Qin, Z.-J. Zhang, H.-J. Liu, Anal. Chim. Act 357 (1997) 127.

[26] V. Cannizzaro, A.R. Bowie, A. Sax, E.P. Achterberg, P.J. Worsfold, Analyst 125 (2000) 51.

[27] Z.-L. Fang, in Flow Injection Separation and Preconcentration, VCH, Weinheim, 1993, Chapter 2, p. 36.

[28] J.C. Miller, J.N. Miller, in: Statistics for Analytical Chemistry, third ed., Ellis Horwood, Chichester, UK, 1993, p. 55 